\title{
Instructional Design using Blogs for Improving Learning Interactivity: A Design Case in Early Childhood Teacher Education Program
}

\author{
Ulfia Rahmi \\ Educational Technology \\ Universitas Negeri Padang \\ Padang, Indonesia \\ ulfia@ fip.unp.ac.id
}

\author{
Syafril \\ Educational Technology \\ Universitas Negeri Padang \\ Padang, Indonesia \\ syafril.alwi@yahoo.com
}

\author{
Azman \\ Educational Technology \\ Universitas Negeri Padang \\ Padang, Indonesia \\ azmalino2001@yahoo.com
}

\author{
Azrul \\ Faculty of Education \\ Universitas Negeri Padang \\ Padang, Indonesia \\ azrulmardin@unp.ac.id
}

\begin{abstract}
This manuscript is a design case in early childhood education program in using blogs to improve learning interactivity. The Optimize using of blogs in instructional design provides an extensive opportunity for early childhood education teachers to interact with lecturer, students and learning materials. The goals of instructional design by using blog is to develop the digital pedagogy skills of early childhood teacher candidate, because this is one of the important competencies developed among other competencies such as professional, social, and individual competencies. The teacher candidate who are on pre-service training are now prepared to deal with students who are familiar with technology, which means that the teachers must be able to adapt the progress that has been made so that their digital pedagogy skills can be accepted by students. Therefore, the teachers' candidate need to be prepared carefully. In this case, the learning designer is responsible for providing space for prospective teachers to be actively involved and familiar with technology.
\end{abstract}

Keywords-instructional design; blog; learning interactivity; early childhood

\section{INTRODUCTION}

The need for digital learning is supported by the availability of digital devices around students. Digital technology is rapidly becoming an essential part of the daily life of many adults [1]. Digital learning is not replaced the role of educators. Thus, the implication is ideal learning in a rich digital environment with interactivity. The higher the students' interactivity with the learning resources, the better the quality of the learning.

Technology, digital media and culture are important aspects of a child's life in a post-industrial society. The problem for early child educators is how to effectively integrate these aspects of the child's life into the provision of play based learning. Traditionally, some studies have considered obstacles to technological uptake of teachers in the early years, or beliefs and attitudes of teachers about the use of technology with young children. An alternative perspective focuses on children's play as a basis for the provision of early childhood curricula and argues that what is needed is just a "new" game concept that is more appropriate to explain the contemporary playing experience of children in post-industrial society [2]. This study provides the meaning that early childhood needs to be learned in the latest way based on technology.

In addition, other researchers conducted coaching on video-based colleagues to promote interaction to prospective early childhood education teachers according to their development [3]. Researchers discussed implications for teacher preparation after conducting research with 19 courses. This study provides a picture for learning prospective teachers of this age child education. At the Faculty of Educational in Universtitas Negeri Padang not all students have the ability as done. Based on the analysis of the students' initial needs and abilities, the researcher improves the learning interactivity through the facilities provided by the university.

If around the students are available various digital-based learning tools, then the demands of lecturers need creative and innovative designing learning activities. So far, the implementation of digital learning has not become a priority and its implementation is more ad hoc because of various factors, so the results obtained less than the maximum. In this manuscript, presented about the experience of doing innovative learning in Education Technology study program, the results show a significant change. The author recommends such a way to prepare prospective teachers of early childhood education. The early childhood period is a critical foundational moment in human development.

Ideal learning for early childhood teacher candidates can adopt various forms of learning conducted by other researchers. Another way that can also be done is to identify the ways that are applied in early childhood education to unlock the teacher's candidate insight that's what they'll do like [2] and [4]. The difference is, [4] takes a two-year collaborative action that investigates the use of digital technology. The findings reveal that collaborative action research projects contribute to empower teachers in using digital technology to support the implementation of new inclusive learning strategies. The use of digital technology enables the implementation of inclusive instructional strategies by providing various ways of representation, action and expression, and involvement, based on the Universal Design framework (UDL). The findings also support the 
adoption of e-inclusion approaches in EFI classes to meet the needs of all learners. These ways can explore how differentiated pedagogy [5]. Therefore, it is necessary to prepare qualified early childhood educator candidates.

Considering the increased influence of digital technologies on technology and technology, [1]. The multiple literacies of children in the 21 st century may be influenced by the increasing importance of digital technology [5]. Prospective teachers should update the development of early childhood education knowledge, therefore, need to habituate information literacy since pre service training. Americans have started and to facilitate the integration of technology into learning in early childhood education they have special programs, [6] calling it an education policy program.

Therefore, it is necessary to specially designed rich learning interactivity as an effort to develop the competence of digital prospective teachers by using blog. Weblogs, or blogs, have rapidly evolved to become a popular and influential form of online micro-publishing and computer mediated communication [7]. Blogs have the potential to be an effective learning resource in college [8]. "Blogging has the potential to be a transformational technology for teaching and learning" [9].

The Web 2.0 era focuses on active users' online participation and interaction. Among the interactive media, blog is one of the representation tools of online knowledge construction. The purpose of this study was to explore behavior patterns and the depth of knowledge construction while using blogs for professional development of teachers. This study combines quantitative content analysis, sequential analysis, and qualitative analysis. We studied how 470 teachers use blogs to interact instructional knowledge before teacher interventions and analyze teacher behavior patterns and the depth of knowledge construction. Based on the behavior patterns found, we see that while blogs can serve as a channel for teachers to share teaching information, the aspects of knowledge construction are limited. We demonstrate this limitation, and provide suggestions on how teacher educators can guide interaction during the course of the training. We also suggest how system developers can customize blogging functions to facilitate online teacher community quality discussions [10]. The authors have done so in educational technology courses, the same can also be done in the early childhood education candidate study program.

\section{LITERATURE REVIEW AND DISCUSS}

\section{A. Learning Interactivity with Blog}

Blogging is best described as a form of micro publishing. Easy to use, from any internet connection point, blogging has become established as a web-based communication tool. Blogging Phenomenon has evolved from its beginnings as a simple publication medium, personal online diaries, to the latest annoying technology, the 'killer app' it has the capacity to engage people in collaborative activities, knowledge sharing, reflection and debate. Many blogs have large and dedicated readers, and blogs have formed a relationship that falls in bloggers according to their shared interests. The paper concludes that blogging has the potential to be a transformational technology for teaching and learning [11].

Digital games are reviewed as emerging tools in educational technology. Factors such as instructional effectiveness, timing of assignments, relationships with the curriculum, students' socioeconomic status, violence in the game, and game mechanics are considered. Although there is considerable variability among studies, a larger overall effect size for the impact of games on learning is found for digital games than for early computer-assist instruction. The study found that digital games are beginning to evolve, people learn from them, and the transfer from game to new task is more closely related to the underlying cognitive process than superficial similarities. However, effective procedures for designing games that generate targeted instructional goals while keeping their entertainment value elusive. The study also determined that the time spent playing digital games should be taken into account in the assessment because of their ability to capture and hold the attention of learners. Finally, the effectiveness of games in providing instruction for students who are difficult to reach may be a very useful field of research and development [10].

\section{B. Digital Pedagogy Skills}

Digital literacy is an important aspect to consider in teacher education as a way to meet the needs of XXI century learners, especially in the context of early childhood where developmental issues must be paramount in making instructional design decisions [12]. The influence of digital technologies on literacy practices of the XXI century may influence the types of literacy young children observe and use to read, write, and communicate [1]. Therefore, new literacies, the skills, strategies, and dispositions to use and adapt to the information and communication technologies, are required when reading and writing on the Internet [5]. Blogging is a useful practice for the development of higher order learning skills, active, learner centered pedagogy, authentic learning, associative thinking, and interactive learning communities.

Blogs typically make central use of the hypertextual facilities of online communication: linking internally between posts, providing links to other web content, and/or linking to other users' blogs [13]. Drawing on the social constructivist educational theories of [14] usefully explicate the four central pedagogic benefits of blogging for students: a) Assisting students to become subject matter experts through a process of regular scouring, filtering and posting, b) increasing student interest and ownership in learning, c) giving students legitimate chances to participate and enculturating them into a community of practice, and d) providing opportunities for diverse perspectives.

Based on these studies and in relation to the current situation, education is in the process of transforming traditional text-based learning into digital format. This multi- 
case study highlights the challenge of overcoming old and new literacy teaching in the context of technology-mediated teaching in the early years of school (children aged 7-8 years). By investigating the relationship between literacy and digital technology in diverse pedagogical contexts, we can grasp the complexities in educational transformations that need to be recognized. Each case shows different focus and objectives of knowledge for early literacy teaching, organization and access to technology and what is seen in teaching. All of these factors result in teaching taking place. Depending on epistemological beliefs, digital competence is taught separately from literacy and is perceived as a separate or integrated goal with literacy that is considered as a means and goal of literacy teaching and learning. Implicit pedagogy with weaker classification and framing conditions that allow for infused approaches utilize digital technology in the practice of multimodal, functional and learner literacy. Furthermore, the initial guidance and weaving of invisible pedagogy highlight the possible ways to harness the potential of digital technology and support children from diverse backgrounds. The balance of teacher and student controls is more affected in terms of technological organization and choice of pedagogical methods. This study expands the current discussion of the relationship between technology and literacy with the understanding that epistemological focus and the context of practice are a necessary tool for problematization, rather than measuring or assessing, practices that arise in early literacy teaching. We conclude that in addition to the heavy investments required in digital technology in schools, there is a need to make room for action for teachers and address the issues of destination, pedagogy and organization around technology [15]. In the world of digital technology today, educators should re-learn how children learn and the way in which the early labor force regulates their learning environment [16].

\section{CONCLUSION}

Based on the results of previous research, interpreted that the level of use of technology by early childhood at home and in school is quite high. Therefore, learning designed for them is also recommended based on technology to be relevant to their daily lives. The implications of prospective early childhood education teachers need to be prepared with relevant competencies for designing early childhood learning based on technology. One way that can be done is to optimize the university facilities that are utilizing blogs to improve the interactivity of learning. The hope, with the usual prospective teachers using the blog will increase their intensity in interacting with technology devices. This paper supports the arguments for the educational use and value of blogging but also highlights the potential limitations and problem areas.

\section{References}

[1] B. Beschorner and A. Hutchison, 'iPads as a literacy teaching tool in early childhood.', Online Submiss., vol. 1, no. 1, pp. 16-24, 2013.

[2] S. Edwards, 'New concepts of play and the problem of technology, digital media and popular-culture integration with play-based learning in early childhood education', Technol. Pedagog. Educ., vol. 25, no. 4, pp. 513532, 2016.

[3] A. S. Kennedy and A. T. Lees, 'Preparing undergraduate pre-service teachers through direct and video-based performance feedback and tiered supports in Early Head Start', Early Child. Educ. J., vol. 44, no. 4, pp. 369-379, 2016.

[4] M. Pellerin, 'E-inclusion in early French immersion classrooms: Using digital technologies to support inclusive practices that meet the needs of all learners', Can. J. Educ., vol. 36, no. 1, p. 44, 2013.

[5] D. J. Leu, C. K. Kinzer, J. L. Coiro, and D. W. Cammack, 'Toward a theory of new literacies emerging from the Internet and other information and communication technologies', Theor. Model. Process. Read., vol. 5, no. 1, pp. 1570-1613, 2004.

[6] S. Cook, 'Integrating Technology in Early Literacy: A Snapshot of Community Innovation in Family Engagement.', New Am., 2016.

[7] J. Jacobs, Uses of Blogs. Peter Lang, 2006.

[8] B. Farmer, A. Yue, and C. Brooks, 'Using blogging for higher order learning in large cohort university teaching: A case study', Australas. $J$. Educ. Technol., vol. 24, no. 2, 2008.

[9] H.-T. Hou, K.-E. Chang, and Y.-T. Sung, 'Using blogs as a professional development tool for teachers: Analysis of interaction behavioral patterns', Interact. Learn. Environ., vol. 17, no. 4, pp. 325-340, 2009.

[10] S. Tobias, J. D. Fletcher, and F. Chen, 'Digital Games as Educational Technology: Promise and Challenges in the Use of Games to Teach.', Educ. Technol., vol. 55, no. 5, pp. 3-12, 2015.

[11] J. B. Williams and J. S. Jacobs, 'Exploring the use of blogs as learning spaces in the higher education sector', Australas. J. Educ. Technol., vol. 20, no. 2, pp. 232-247, 2004.

[12] L. W. Langub and A. Lokey-Vega, 'Rethinking Instructional Technology to Improve Pedagogy for Digital Literacy: A Design Case in a Graduate Early Childhood Education Course', TechTrends, pp. 19, 2017.

[13] M. Tremayne, Blogging, citizenship, and the future of media. Routledge, 2012.

[14] R. E. Ferdig and K. D. Trammell, 'Content delivery in the'Blogosphere', J. (Technological Horizons Educ., vol. 31, no. 7, p. 12, 2004.

[15] S. Sofkova Hashemi and K. Cederlund, 'Making room for the transformation of literacy instruction in the digital classroom', J. Early Child. Lit., vol. 17, no. 2, pp. 221-253, 2017.

[16] I. Palaiologou, 'Children under five and digital technologies: implications for early years pedagogy', Eur. Early Child. Educ. Res. J., vol. 24, no. 1, pp. 5-24, 2016. 